WellBeing International

WBI Studies Repository

2014

\title{
Applying Ethological and Health Indicators to Practical Animal Welfare Assessment
}

F. Wemelsfelder

Scotland's Rural College

S. Mullan

University of Bristol

Follow this and additional works at: https://www.wellbeingintlstudiesrepository.org/acwp_awap

Part of the Animal Studies Commons, Behavior and Ethology Commons, and the Comparative Psychology Commons

\section{Recommended Citation}

Wemelsfelder, F., \& Mullan, S. (2014). Applying ethological and health indicators to practical animal welfare assessment. Scientific and Technical Review, Office International des Epizooties, 33, 111-20.

This material is brought to you for free and open access by WellBeing International. It has been accepted for inclusion by an authorized administrator of the WBI Studies Repository. For more information, please contact wbisr-info@wellbeingintl.org.

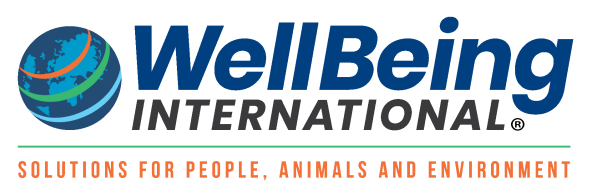




\title{
Applying Ethological and Health Indicators to Practical Animal Welfare Assessment
}

\author{
F. Wemelsfelder ${ }^{1} \&$ S. Mullan ${ }^{2}$ \\ ${ }^{1}$ Scotland's Rural College \\ ${ }^{2}$ University of Bristol
}

\section{KEYWORDS}

animal welfare assessment, ethology, on-farm welfare management, positive animal welfare, practical animal welfare assessment, qualitative behavioural assessment, scientific validation

\begin{abstract}
There is a growing effort worldwide to develop objective indicators for animal welfare assessment, which provide information on an animal's quality of life, are scientifically trustworthy, and can readily be used in practice by professionals. Animals are sentient beings capable of positive and negative emotion, and so these indicators should be sensitive not only to their physical health, but also to their experience of the conditions in which they live. This paper provides an outline of ethological research aimed at developing practical welfare assessment protocols. The first section focuses on the development and validation of welfare indicators generally, in terms of their relevance to animal well-being, their interobserver reliability, and the confidence with which the prevalence of described features can be estimated. Challenges in this work include accounting for the ways in which welfare measures may fluctuate over time, and identifying measures suited to monitoring positive welfare states. The second section focuses more specifically on qualitative welfare indicators, which assess the 'whole animal' and describe the expressive qualities of its demeanour (e.g. anxious, content). Such indicators must be validated in the same way as other health and behaviour indicators, with the added challenge of finding appropriate methods of measurement. The potential contribution of qualitative indicators, however, is to disclose an emotional richness in animals that helps to interpret information provided by other indicators, thus enhancing the validity of welfare assessment protocols. In conclusion, the paper emphasises the importance of integrating such different perspectives, showing that new knowledge of animals and new ways of relating to animals are both needed for the successful development of practical welfare assessment tools.
\end{abstract}

\section{Introduction}

There is a rapidly growing motivation to better understand how animals experience their world, and how they are affected by human presence, activity and control. Over the past 40 years or so, the concept of animal welfare has evolved from focusing primarily on an animal's physical health and ability to cope (1), to recognising that animals are sentient beings capable of experiencing positive and negative emotions 
(2). The social and ethical dimensions of animal welfare, which are concerned with how human society morally regards and treats non-human animals, are also increasingly being recognised $(3,4)$. Thus, the United Kingdom (UK) Farm Animal Welfare Council (5) has suggested that standards for the welfare of animals under our care should not only ensure that these animals have a 'life worth living', but may also aspire towards giving them a 'good life' - a concept emphasising the importance of positive experiences for good welfare.

Different animal species may thrive in different conditions, so it is crucial to find indicators that truly reflect the animals' needs and interests (6). Much effort is being invested worldwide in the development of welfare indicators that reflect an animal's quality of life, are scientifically trustworthy, and can readily be used in practice by professionals such as animal caretakers, farmers, veterinarians and welfare inspectors. Scientists are integrating insights from behavioural and cognitive science, neuroscience, stress physiology, and animal psychology, and are producing growing evidence that animals are intelligent beings capable of complex emotion $(7,8,9)$. This implies that sensitive protocols are needed, which tell us not only whether an animal is severely stressed, but also whether it is in a positive state, or perhaps lethargic and bored.

Detecting such differences in how animals experience husbandry systems is most likely to be achieved through close observation of their behaviour in varying circumstances (10), and research groups across the world are investigating which behavioural indicators provide the best and most reliable information on welfare. Accordingly, our knowledge of practical welfare assessment is growing, and the aim of this paper is to provide an outline of this area of work. The paper consists of two main sections. The first section focuses on key issues in the development and validation of welfare indicators generally. The second section focuses more specifically on how these issues apply to qualitative welfare indicators. Such indicators are less commonly used but, when applied appropriately, have the potential to make an important contribution to assessing animals' quality of life. The paper concludes by looking ahead to what may be new directions and future challenges.

\section{The development and validation of practical welfare indicators}

The development of practical welfare assessment protocols has been researched most extensively in farmed animals. However, the principles underlying such protocols can also be applied to other species, and be adjusted to suit different domains of animal use and management (11). Early research into onfarm welfare assessment focused mostly on 'inputs' to animal welfare, i.e. the physical, husbandry and management resources present on a farm (12). More recently, however, there has been increasing interest in assessing welfare 'outcomes', i.e. how those resources actually affect the animal. Through observation of animals in different husbandry systems we can assess their health and welfare more directly and in greater detail. Various protocols have been developed recently which aim to provide a more holistic welfare assessment of animals on a farm, integrating the results from a range of indicators into an overall welfare score or category (13).

The time available to make such welfare assessments, however, is usually limited in commercial contexts. There is thus a need to identify smaller sets of representative indicators that will still succeed in effectively addressing major animal health and welfare concerns (14). These indicators are likely to relate to an animal's physical health, as reflected by, for example, body condition, body lesions, extent of lameness, signs of disease or chronic stress, and abnormalities such as feather loss in hens and tailbiting injuries in pigs. They are also likely to focus on key aspects of the animal's behaviour, e.g. the fulfilment of basic needs such as feeding and resting, social interaction with other animals, exploration of novel objects and the farm environment, relationship with stock handlers, and, as discussed in the second part of this paper which explores 'Qualitative welfare indicators', an animal's overall expressive 
demeanour. If such indicators are to provide credible standards for animal welfare, either on their own or as part of a welfare assessment protocol, it is imperative that they be validated in a number of ways. Below, the paper will discuss a number of key validation requirements, and the challenges to which these give rise.

\section{Validating indicators of animal well-being}

The primary requirement for any welfare indicator is that it needs to provide meaningful information on the wellbeing of animals, i.e. it must have 'construct validity'. As discussed above, what is understood by 'well-being' is multi-dimensional; however, generally it is taken to refer to an animal's affective experience of a condition or situation. By undertaking particular experiments, or referring to theoretical frameworks $(15,16,17)$, it can be deduced that certain indicators reflect certain kinds of experience. For example, to validate gait assessment as an indicator for broiler welfare, researchers tested the pain associated with different levels of impaired mobility by recording the birds' self-selection of analgesic drugs (18), and by recording the negative impacts of impaired mobility on behavioural indicators such as lying down and feeding (19).

Another way of identifying indicators that reliably represent key elements of an animal's welfare status is to investigate what animals choose to do when given the opportunity (6). This can be done in controlled experimental conditions, e.g. by providing pigs with a choice of substrates in order to identify which ones they prefer (20), or in more diverse, semi-natural environments, e.g. by examining how pigs interact with natural substrates (21). If the animals are observed to display a consistent preference for certain activities or resources, the presence or absence of these activities/resources can be used as a welfare indicator; an example is the motivation of captive mink to find water in which to swim (22). Moreover, animals may not only prefer certain things, but there may be consistent differences in the preferences of individuals within a group (23). For this reason, one recently proposed welfare assessment protocol focuses on providing a diversity of resources to animals in their farm environment, offering a greater choice of activity. Such diversity can be assessed by recording what facilities are available on a farm, and the animals' use of those facilities (24).

\section{Inter-observer reliability}

Assuming that potential welfare indicators have the meaning we attribute to them, a second criterion for validating such indicators is their inter-observer reliability, i.e. how well assessors agree in scoring these measures. Many measures were originally developed for research purposes, but were subsequently adapted for less controlled, more time-constrained practical applications. For example, the research literature reports a range of measures for fearfulness in animals (see 25 for a review) and of these the indicator 'response to novel object' has been adapted for assessing laying-hen welfare on farms (26). However, the scoring systems and scales used in research often need to be adapted and streamlined for practical use, so that they can be reliably used by assessor teams across the world. How much standardisation is necessary will depend on how an organisation intends to use these systems, and on the funding available for training. It is increasingly apparent that training assessors to achieve consistent agreement when using welfare indicators requires considerable time and effort, as part of a dedicated programme $(27,28)$. This is true both for quite straightforward physical indicators, such as body lesions and dirtiness in pigs (29), and for more complex behavioural assessments, such as resting behaviour in dairy cattle (30). Observers tend to agree more easily when indicators are clearly defined (30) and when scoring systems are simplified (31). Finding such ways of improving inter-observer reliability is fundamental to developing valid welfare assessment protocols. 


\section{Managing the uncertainty of partial assessments}

When assessing animals on farms, in zoos, or in laboratories, time and cost constraints usually restrict observations to a limited number of individuals among the animals present. A third form of validation therefore involves addressing the level of uncertainty of such estimates through mathematical analysis, so that sub-group outcomes can reliably be extrapolated to the group as a whole (32). The larger the sample of animals that can be assessed for an indicator, the more accurate such extrapolations will be.

Obviously, indicators with high levels of inter-observer reliability that are observed in all or in a very large sample of animals provide the most accurate estimates of the proportion of animals exhibiting particular features. Such outcomes can then be used to classify a farm in accordance with legislated or voluntary welfare standards, or to track changes over time. An example of such an indicator is 'whole herd' mobility scoring in dairy cows, using a 4-point scale. This scoring system is advocated in the UK to monitor lameness, and the effect of improvement strategies undertaken by farmers (33).

However, as the inter-observer reliability of indicators falls, and/or uncertainty over the proportionate occurrence of particular features increases, these indicators become less suitable for imposing and monitoring standards of welfare. Nevertheless, they can be used to encourage interest in animal welfare among the people who work with the animals every day, to improve their awareness and management of factors affecting their animals' well-being. On the other hand, if inter-observer reliability is adequate, it may be possible to combine welfare scores from small sample sizes across many farms, or other animal units such as laboratories or zoos, and so obtain reliable aggregated scores. This may be useful for evaluating animal welfare in voluntary schemes (e.g. farm assurance), or at the national level (14).

\section{Monitoring welfare over time: automated assessment}

Practical assessment of welfare outcomes is thus an active area of research, which still faces numerous challenges. One challenge is fluctuation over time - protocols may assess welfare on a particular day, but little is known about how outcomes vary with cycles and seasons throughout the year, and what such shifts mean in terms of welfare. Gaining such insight would require regular repeat assessments, which would incur great financial and time costs and do not seem feasible. Institutional records can provide some of the required information, but only if their quality is not compromised by poor recording techniques or inadequate training (34). Some of the challenges associated with time and cost may be overcome by automated monitoring systems, such as, for example, those used for monitoring foot-pad dermatitis in broiler chickens at slaughterhouses (35). Automated assessments could also play an important role in overcoming challenges posed by extensive outdoor systems, where animals have limited contact with people and can be difficult to locate (36). Automated monitoring of these animals' activity patterns may alert stock handlers to 'out of normal range' problems with the health or behavior of their animals (37).

\section{Indicators of positive emotion}

Another important challenge is the development of indicators for positive emotion and welfare, i.e. measures that reflect animals having a 'good life' (5). Recently developed frameworks discuss positive emotion as part of a functional cognitive approach embedded in neuroscience $(8,17,38)$. These frameworks suggest potential indicators for positive emotion, such as optimistic cognitive bias, which measures the extent to which animals expect to be positively rewarded (39), and various behavioural categories, such as play, exploration, vocalisation, and social and self-grooming behaviour $(17,38)$. However, many of these indicators have not yet been sufficiently validated to be ready to apply in practice. Another potential problem is that some behaviours occur too infrequently to be useful in assessment protocols (e.g. play, vocalisations), even when opportunities to express them are available. 
Interest is therefore growing in more continuous dynamic measures, such as the percentage of eye-white in an animal's total visible eye area (40), ear and tail positions (41, 42), and also qualitative behaviour assessment, which describes the overall expressive quality of behaviour (43; see below). Monitoring and promoting positive experiences is clearly a good way to improve welfare, and research in this area is considered to be of prime importance for advancing animal welfare (44).

\section{Qualitative welfare indicators}

The principles of validation and application described above are equally true for qualitative indicators of welfare. However, such indicators differ from other indicators in essential ways, and there are specific concerns surrounding their scientific validation, as well as specific challenges that arise in their practical application. A closer examination of the nature of qualitative welfare indicators will help to address these concerns.

\section{The expressivity of the whole animal}

The key characteristic of qualitative assessment is that it addresses the whole animal, as a single integrated unit of observation, while the animal moves around and interacts with its surroundings. It does not, like other indicators, focus on particular physical elements of behaviour, or on a combination of such elements, but always on the dynamic whole animal. When interacting directly with animals, we do not perceive them as complex compartmentalized systems in the way that scientific models do. We simply see the animal as a whole, responsive, sentient being $(45,46)$. This is not mere 'lay perception'; rather it underlies the moral and conceptual landscape of animal welfare science. We are concerned for animals, not their brains, as it is the animals, not their brains, which experience pain, stress or joy $(47,48)$. All measurements of animal health, behavior and welfare have eventually to be weighed up and integrated qualitatively at the 'whole-animal' level $(11,13)$. Thus, assessing animals as whole sentient beings is important, and may contribute essential integrative information to assist in judging their quality of life.

The starting point for such assessment is that the whole animal, unlike its physical body parts, is psychologically expressive. It is not the tail, ear, or facial features per se that have expressive meaning, it is how the animal holds and moves those features dynamically that generates this meaning. Such expressivity, or 'body language', communicates the quality of an animal's engagement with its surroundings, i.e. how it perceives and responds to (and thus experiences) the environment and other animals in its vicinity. We can observe this over time, and judge what it tells us about the animal's state; for example, whether the animal is lively, curious and relaxed, or fearful, hostile and tense (43). Such characterisations are directly relevant to an animal's experience, implying that this experience may not be as private and hidden from view as is routinely assumed by many scientists. But, whatever one's stance, perceiving animals as relaxed or anxious is clearly relevant to assessing their well-being, and could add to the validity and discerning power of welfare assessment protocols. However, it would be imprudent to assume that such perceptions can, by themselves, sum up an animal's overall welfare (49). It is best to integrate qualitative assessments with other indicators of health and welfare into balanced welfare protocols.

\section{The scientific validation of whole animal assessments}

To achieve such integration, it is necessary to submit qualitative judgements of animal expression to measurement and to investigate their association with biological organisation (50,51). Use of qualitative assessment in animal science is not new. Ethologists such as Jane Goodall (52) and Joan StevensonHinde (53), for example, were pioneers in articulating that animals have qualitatively different individual styles of behaving. This work merged with the wider field of animal temperament and personality 
research, where quantification of expressive traits and integration of these with biological organization has been gaining scientific credibility (54). Various research teams then extended the use of personality descriptors (e.g. friendly, fearful) for the purpose of monitoring well-being in individual animals in zoos $(55,56,57)$, scientific laboratories $(58)$, and companion animal homes $(59,60)$. Despite the success of this work, however, qualitative assessments - in their reliance on human integrative judgement - are still frequently referred to as 'subjective' (61). This contrasts them with the assumed greater objectivity of other types of measurement, and keeps alive the suspicion that they are anthropomorphic and unworthy of full scientific status.

This view is, however, increasingly regarded as outdated, both philosophically and scientifically $(50,62)$. Recognition is growing that recording physical indicators also tends to involve some qualitative judgement (e.g. scoring whether animals are 'very dirty' or 'badly scratched'), and that part- and whole-animal assessments are better regarded as interdependent, complementary types of insight. Wemelsfelder and colleagues $(63,64)$ hypothesised that qualitative assessments are not merely abstract inferences of behavioural style, but rely on direct observation of a continuous stream of dynamic behavioural expressivity in animals. To investigate this premise, they employed a freechoice profiling (FCP) methodology, which asked groups of people to generate their own terms to score the body language of the animals which they were observing. This meant that people had to interpret the animals' expressions for themselves, rather than relying on and being constrained by an experimenter's terms, which allowed for a more thorough scientific examination of qualitative assessments.

Different research teams across the world have since applied this approach to pigs, cattle, poultry, sheep, buffalo, horses, ponies, dogs and elephants, and have consistently found good agreement between observers' assessments, even when these observers had different backgrounds and levels of experience (e.g. 65, 66, 67). Observers' assessments were found to correlate meaningfully with physical behaviours and physiological indices of stress $(68,69,70)$, and not to be unduly affected by the environmental background in which the animals were being viewed (71). Such outcomes support the view that qualitative whole-animal assessment is not mere 'subjective perception': it can function as a scientific method and has direct relevance to understanding animals and their perspective on the world.

\section{The practical application of qualitative welfare indicators}

The question then is how judgements of animal expressivity can be used in practical welfare assessment and management. For regular monitoring of welfare and integration with assessment protocols, it is clearly not feasible to let assessors use their own terms. Some form of standardisation is necessary. An agreed list of suitable terms can be created through a formal FCP exercise, or through a literature search and discussion with caretakers and other stakeholders (e.g. veterinarians). Skilful appraisal of animal expressions underlies traditional stockmanship. For example, a good stock handler can recognise an animal that is 'not right' from a considerable distance. Creating lists of qualitative terms is thus an excellent way to both empower animal caretakers and enrich vocabularies for managing welfare in laboratories, zoos and on farms (57).

It is important to stay flexible in adding or removing terms to and from existing lists, in order to suit the language and culture of particular countries, or the characteristics of particular industries. However, enough positive and negative descriptors should always be included to cover the expressive repertoire of each animal species under study. From a whole-animal perspective, the aim is not to identify a minimal set of core terms, but to capture larger patterns of expression and their context through a range of multilayered terms. Knowing how to apply these terms can be enhanced by clear instructions, brief characterisations of each term, and supportive video material. The descriptive richness of qualitative terminologies gives this type of assessment the power to address dynamic aspects of welfare for which 
specific physical indicators might not easily be found. This applies to positive welfare, but also generally to subtle yet important differentiations, such as between relaxation and apathy, or between positive and negative excitement $(72,73)$.

A major challenge in implementing such qualitative terminologies, however, is to support them with reliable scoring methods (74). Qualitative judgement is integrative, comparative and tied to its context, and does not rely on adding up numerical units. One could try to anchor the scoring of terms by categorising scoring levels in some way (e.g. 'not present', 'moderate' or 'severe'); however, this would be likely to interfere with the qualitative integration process and limit its proficiency. It seems preferable to use unstructured visual analogue scales to score the different terms, and these scores can be integrated statistically through multivariate analysis. This analysis generates dimensions of animal expression (e.g. 'relaxed/content-tense/anxious'), and places each animal assessed somewhere along the continuum of these dimensions. The welfare implications of an animal's position on the expressive continuum - for example, at what point a high 'tense/anxious' score becomes a welfare concern - should be anchored with descriptions and examples, and these parameters can then be incorporated into welfare assessment protocols.

In practical farm and laboratory settings it will often be necessary to assess animals at the group level and, although this requires more complex integration of expressive information, studies show that it can be done reliably $(49,75,76)$. However, not all studies show good interobserver reliability (77), and onfarm assessments of test-retest reliability have revealed both good and moderate results (78). What is clear, above all, is that continuing efforts by caretaker/assessor teams to align their understanding of terms, and their use of these terms for scoring, are crucial. This does not differ from the requirements of other types of indicators to ensure that their use is reliable, and the development of specific training programmes, such as those used for other indicators, would be highly beneficial. Yet, apart from meeting such formal standards, focusing on animal expressions is also a goal in itself. It increases our sensitivity to how animals communicate, and to what may be effective ways of improving their quality of life. Qualitative assessment can be a platform for such shared learning. Developing this potential is a goal of future work.

\section{Conclusion}

From this brief review, it is clear that developing indicators for animal welfare that are objective, workable and relevant to animal care is a complex task. However, as this area of work develops, new indicators emerge and deepen our understanding of animal well-being. Recent work on laboratory animals, for example, has led to the development of systems for coding facial expressions indicative of pain in mice, rats and rabbits (79). Although these systems are based on physical facial features, their focus on subtle expressive detail suggests a growing potential for integrating specific physical assessments with qualitative assessments. With the former focusing on functional biological organisation and the latter on whole-animal experience, these two types of assessment can be mapped onto each other, enhancing the interpretation and validation of both methods $(65,73)$.

Such integration is but one example of a much-needed merging of perspectives and expertise to improve animals' lives (80). Science may identify reliable indicators, but how effective these are as aids to improving animal welfare ultimately depends on how humans engage with animals in daily life, depending on their skills, attitudes and efforts $(81,82,83)$. We are used to framing that engagement in terms of control, but increasingly academics across disciplines are encouraging us to think more inclusively of animals as members of 'more-than-human' communities (62). Thus, both new knowledge of animals and new ways of relating to them are needed to make practical welfare assessment tools a success. 
Monitoring welfare standards is an important first step, but only a greater sensitivity and responsibility towards animals will make these standards work.

\section{References}

1. Broom D. (1988). - The scientific assessment of animal welfare. Appl. anim. Behav. Sci., 20, 5-19.

2. Duncan I.J.H. (2006). - The changing concept of animal sentience. Appl. anim. Behav. Sci., 100, 1119.

3. Fraser D., Weary D.M., Pajor E.A. \& Milligan B.N. (1997). - A scientific conception of animal welfare that reflects ethical concerns. Anim. Welf., 6, 187-205.

4. Sandøe P., Christiansen S.B. \& Appleby M.C. (2003). - Farm animal welfare: the interaction of ethical questions and animal welfare science. Anim. Welf., 12 (4), 469-478.

5. Farm Animal Welfare Council (FAWC) (2009). - Report on the welfare of farmed animals in Great Britain: past, present and future. FAWC, London.

6. Dawkins M.S. (2006). - Through animal eyes: what behavior tells us. Appl. anim. Behav. Sci., 100, 410.

7. Boissy A., Arnould C., Chaillou E., Desire L., Duvaux-Ponter C., Greiveldinger L., Leterrier C., Richard S., Roussel S., Saint-Dizier H., Meunier-Salaun M.C., Valance D. \& Veissier I. (2007). Emotions and cognition: a new approach to animal welfare. Anim. Welf., 16, 37-43.

8. Mendl M., Burman O.H.P. \& Paul E.S. (2010). - An integrative and functional framework for the study of animal emotion and mood. Proc. roy. Soc. Lond., B, biol. Sci., 277, 2895-2904.

9. Green T.C. \& Mellor D.J. (2011). - Extending ideas about animal welfare assessment to include 'quality of life' and related concepts. N.Z. vet. J., 59 (6), 263-271.

10. Christiansen S.B. \& Forkman B. (2007). - Assessment of animal welfare in a veterinary context: a call for ethologists. Appl. anim. Behav. Sci., 106, 203-220.

11. Main D.C.J., Kent J.P., Wemelsfelder F., Ofner E. \& Tuyttens F.A.M. (2003). - Applications for methods of on-farm welfare assessment. Anim. Welf., 12, 523-528.

12. Bartussek H. (1999). - A review of the animal needs index (ANI) for the assessment of animals' wellbeing in the housing systems for Austrian proprietary products and legislation. Livest. Prod. Sci., 61, 179-192.

13. Botreau R., Veissier I. \& Perny P. (2009). - Overall assessment of animal welfare: strategy adopted in Welfare Quality ${ }^{\circ}$. Anim. Welf., 18, 363-370.

14. Main D.C.J., Mullan S., Atkinson C., Bond A., Cooper M., Fraser A. \& Browne W.J. (2012). - Welfare outcomes assessment in laying hen farm assurance schemes. Anim. Welf., 21, 389-396.

15. Fraser D. \& Duncan I.J.H. (1998). - 'Pleasures', 'pains' and animal welfare: toward a natural history of affect. Anim. Welf., 7, 383-396.

16. Mason G.J. \& Veasy J.S. (2010). - How should the psychological well-being of zoo elephants be objectively investigated? Zoo Biol., 29 (2), 237-255.

17. Mellor D.J. (2012). - Animal emotions, behaviour and the promotion of positive welfare states. N.Z. vet. J., 60, 1-8.

18. Danbury T.C., Weeks C.A., Chambers J.P., Waterman-Pearson A.E. \& Kestin S.C. (2000). - Selfselection of the analgesic drug carprofen by lame broiler chickens. Vet. Rec., 146, 307-311.

19. Weeks C.A., Danbury T.D., Davies H.C., Hunt P. \& Kestin S.C. (2000). - The behaviour of broiler chickens and its modification by lameness. Appl. anim. Behav. Sci., 67, 111-125.

20. Beattie V.E., Walker N. \& Sneddon I.A. (1998). - Preference testing of substrates by growing pigs. Anim. Welf., 7, 27-34. 
21. Stolba A. \& Woodgush D.G.M. (1989). - The behaviour of pigs in a semi-natural environment. Anim. Prod., 48, 419-425.

22. Mason G., Cooper J. \& Clarebrough C. (2001). - Frustrations of fur-farmed mink. Nature, 410 (6824), 35-36.

23. Nicol C.J., Caplen G., Statham P. \& Browne W.J. (2011). - Decisions about foraging and risk tradeoffs in chickens are associated with individual somatic response profiles. Anim. Behav., 82, 255-262.

24. Edgar J.L., Mullan S.M., Pritchard J.C., McFarlane U.J.C. \& Main D.C.J. (2013). - Towards a 'good life' for farm animals: development of a resource tier framework to achieve positive welfare for laying hens. Animals, 3, 584-605.

25. Forkman B., Boissy A., Meunier-Salauen M.C., Canali E. \& Jones R.B. (2007). - A critical review of fear tests used on cattle, pigs, sheep, poultry and horses. Physiol. Behav., 92, 340-374.

26. Welfare Quality ${ }^{\circledR}$ Consortium (2009). - Assessment protocol for hens. National Ecological Network, the Hague, the Netherlands.

27. Knierim U. \& Winckler C. (2009). - On-farm welfare assessment in cattle: validity, reliability and feasibility issues and future perspectives with special regard to the Welfare Quality ${ }^{\circledR}$ approach. Anim. Welf., 18, 451-458.

28. Vasseur E., Gibbons J., Rushen J. \& de Passille A.M. (2013). - Development and implementation of a training program to ensure high repeatability of body condition scoring of dairy cows. J. Dairy Sci., 96 (7), 4725-4737.

29. Mullan S.M., Edwards S.A., Butterworth A., Whay H.R \& Main D.C.J. (2011). - Inter-observer reliability testing of pig welfare outcome measures proposed for inclusion within farm assurance schemes. Vet J., 190 (2), e100-e109.

30. Plesch G., Broerkens N., Laister S., Winckler C. \& Knierim U. (2010). - Reliability and feasibility of selected measures concerning resting behaviour for the on-farm welfare assessment in dairy cows. Appl. anim. Behav. Sci., 126, 19-26.

31. Channon A., Walker A., Pfau T., Sheldon I. \& Wilson A. (2009). - Variability of Manson and Leaver locomotion scores assigned to dairy cows by different observers. Vet. Rec., 164, 388-392.

32. Mullan S., Browne W.J., Edwards S.A., Whay H.R., Butterworth A. \& Main D.C.J. (2009). - The effect of sampling strategy on the estimated prevalence of welfare outcome measures on finishing pig farms. Appl. anim. Behav. Sci., 119, 39-48.

33. DairyCo. (2013). - Mobility scoring. DairyCo., Stoneleigh, United Kingdom. Available at: www.dairyco.org.uk/technicalinformation/animal-health-

welfare/lameness/husbandryprevention/mobility-scoring/ (accessed on 10 July 2013).

34. Mullan S., Edwards S., Whay H.R., Butterworth A. \& Main D.C.J. (2009). - Interdependence of welfare outcome measures and potential confounding factors on finishing pig farms. Appl. anim. Behav. Sci., 121, 25-31.

35. Vanderhasselt R.F., Sprenger M., Duchateau L. \& Tuyttens F.A.M. (2013). - Automated assessment of footpad dermatitis in broiler chickens at the slaughter-line: evaluation and correspondence with human expert scores. Poult. Sci., 92, 12-18.

36. Turner S.P. \& Dwyer C.M. (2007). - Welfare assessment of extensive animals: challenges and opportunities. Anim. Welf., 16, 192-198.

37. Rushen J., Chapinal N. \& de Passille A.M. (2012). - Automated monitoring of behavioural-based animal welfare indicators. Anim. Welf., 21 (3), 339-350.

38. Boissy A., Manteuffel G., Jensen M.B., Moe R.O., Spruijt B., Keeling L.J., Winckler C., Forkman B., Dimitrov I., Langbein J., Bakken M., Veissier I. \& Aubert A. (2007). - Assessment of positive emotions in animals to improve their welfare. Physiol. Behav., 92, 375-397.

39. Mendl M., Burman O.H.P., Parker R.M.A. \& Paul E.S. (2009). - Cognitive bias as an indicator of animal emotion and welfare: emerging evidence and underlying mechanisms. Appl. anim. Behav. Sci., 118, 161-181. 
40. Sandem A.I., Braastad B.O. \& Boe K.E. (2002). - Eye white may indicate emotional state on a frustration-contentedness axis in dairy cows. Appl. anim. Behav. Sci., 79, 1-10.

41. Reefmann N., Kaszas F.B., Wechsler B. \& Gygax L. (2009). - Ear and tail postures as indicators of emotional valence in sheep. Appl. anim. Behav. Sci., 118, 199-207.

42. Reimert I., Bolhuis J.E., Kemp B. \& Rodenburg T.B. (2013). - Indicators of positive and negative emotions and emotional contagion in pigs. Physiol. Behav., 109, 42-50.

43. Wemelsfelder F. (2007). - How animals communicate quality of life: the qualitative assessment of animal behaviour. Anim. Welf., 16, 25-31.

44. Yeates J.W. \& Main D.C.J. (2008). - Assessment of positive welfare: a review. Vet. J., 175 (3), 293300.

45. Hearne V. (1986). - Adam's task: calling animals by name. Heinemann, London.

46. Sanders C.R. (2003). - Actions speak louder than words: close relationships between humans and non-human animals. Symb. Interact., 26, 405-426.

47. Midgley M. (1983). - Animals and why they matter. University of Georgia Press, Athens, Georgia.

48. Acampora R.R. (2006). - Corporal compassion. Animal ethics and philosophy of body. University of Pittsburgh Press, Pennsylvania.

49. Andreasen S.N., Wemelsfelder F., Sandøe P. \& Forkman B. (2013). - The correlation of qualitative behaviour assessments with Welfare Quality ${ }^{\circledR}$ protocol outcomes in on-farm welfare assessment of dairy cattle. Appl. anim. Behav. Sci., 143, 9-17.

50. Meagher R.K. (2009). - Observer ratings: validity and value as a tool for animal welfare research. Appl. anim. Behav. Sci., 199, 1-14.

51. Beausoleil N.J. \& Mellor D.J. (2012). - Complementary roles for systematic analytical evaluation and qualitative whole animal profiling in welfare assessment for three Rs applications. In ALTEX: Proc. of the 8th World Congress on Alternatives and Animal Use in the Life Sciences, Montreal 2011. Springer Spektrum, Heidelberg, Germany, 455-460. Available at: www.altex.ch/ALTEXProceedings/Proceedings.98.html?iid=2/ (accessed on 17 June 2013).

52. Goodall J. (1990). - Through a window: thirty years with the chimpanzees of Gombe. Phoenix, London.

53. Stevenson-Hinde J. (1983). - Individual characteristics: a statement of the problem. In Primate social relationships: an integrated approach (R.A. Hinde, ed.). Blackwell Scientific Publications, Oxford, 2834.

54. Gosling S.D. (2001). - From mice to men: what can we learn about personality from animal research? Psychol. Bull., 127, 45-86.

55. Carlstead K., Fraser J., Bennett C. \& Kleiman D.G. (1999). - Black rhinoceros (Diceros bicornis) in US zoos: II. Behavior, breeding success, and mortality in relation to housing facilities. Zoo Biol., 18 (1), 35-52.

56. Weiss A., King J.E. \& Perkins L. (2006). - Personality and subjective well-being in orangutans (Pongo pygmaeus and Pongo abelii). J. Pers. soc. Psychol., 90 (3), 501-511.

57. Whitham J.C. \& Wielebnowski N. (2009). - Animal-based welfare monitoring: using keeper ratings as an assessment tool. Zoo Biol., 28, 545-560.

58. Morton D.B. \& Griffiths P.H.M. (1985). - Guidelines for the recognition of pain, distress and discomfort in experimental animals and an hypothesis for assessment. Vet. Rec., 116, 431-436.

59. Kessler M.R. \& Turner D.C. (1997). - Stress and adaptation of cats (Felis silvestris catus) housed singly, in pairs and in groups in boarding catteries. Anim. Welf., 6, 243-254.

60. Wiseman-Orr M.L., Scott E.M., Reid J. \& Nolan A.M. (2006). - Validation of a structured questionnaire as an instrument to measure chronic pain in dogs on the basis of effects on healthrelated quality of life. Am. J. vet. Res., 67, 1826-1836.

61. Hall C., Huws N., White C., Taylor E., Owen H. \& McGreevy P. (2013). - Assessment of ridden horse behavior. J. vet. Behav., 8, 62-73. 
62. Birke L.I.A. \& Hockenhull J. (2012). - Crossing boundaries: investigating human-animal relationships. Brill, Leiden, the Netherlands.

63. Wemelsfelder F., Hunter E.A., Mendl M.T. \& Lawrence A.B. (2000). - The spontaneous qualitative assessment of behavioural expressions in pigs: first explorations of a novel methodology for integrative animal welfare measurement. Appl. anim. Behav. Sci., 67, 193-215.

64. Wemelsfelder F., Hunter E.A., Mendl M.T. \& Lawrence A.B. (2001). - Assessing the 'whole animal': a free choice profiling approach. Anim. Behav., 62, 209-220.

65. Minero M., Tosi M.V., Canali E. \& Wemelsfelder F. (2009). - Quantitative and qualitative assessment of the response of foals to the presence of an unfamiliar human. Appl. anim. Behav. Sci., 116, 74-81.

66. Wemelsfelder F., Hunter A.S., Paul E.S. \& Lawrence A.B. (2012). - Assessing pig body language: agreement and consistency between pig farmers, veterinarians, and animal activists. J. Anim. Sci., 90, 3652-3665.

67. Napolitano F., De Rosa G., Grasso F. \& Wemelsfelder F. (2012). - Qualitative behaviour assessment of dairy buffalos (Bubalus bubalis). Appl. anim. Behav. Sci., 141, 91-100.

68. Stockman C.A., Collins T., Barnes A.L., Miller D., Wickham S.L., Beatty D.T., Blache D., Wemelsfelder F. \& Fleming P.A. (2011). - Qualitative behavioural assessment and quantitative physiological measurement of cattle naive and habituated to road transport. Anim. Prod. Sci., 51, 240-249.

69. Rutherford K.M.D., Donald R.D., Lawrence A.B. \& Wemelsfelder F. (2012). - Qualitative behavioural assessment of emotionality in pigs. Appl. anim. Behav. Sci., 139, 218-224.

70. Wickham S.L., Collins T., Barnes A.L., Miller D.W., Beatty D.T., Stockman C., Wemelsfelder F. \& Fleming P.A. (2012). - Qualitative behavioral assessment of transportnaive and transport-habituated sheep. J. Anim. Sci., 90 (12), 4523-4535.

71. Wemelsfelder F., Nevison I. \& Lawrence A.B. (2009). - The effect of perceived environmental background on qualitative assessments of pig behaviour. Anim. Behav., 78, 477-484.

72. Napolitano F., Knierim U., Grasso F. \& De Rosa G. (2009). - Positive indicators of cattle welfare and their applicability to on-farm protocols. Ital. J. anim. Sci., 8, 355-365.

73. Napolitano F., De Rosa G., Braghieri A., Grasso F., Bordi A. \& Wemelsfelder F. (2008). - The qualitative assessment of responsiveness to environmental challenge in horses and ponies. Appl. anim. Behav. Sci., 109, 342-356.

74. Scott E.M., Nolan A.M., Reid J. \& Wiseman-Orr M.L. (2007). - Can we really measure animal quality of life? Methodologies for measuring quality of life in people and other animals. Anim. Welf., 16, 1724.

75. Wemelsfelder F., Knierim U., Schulze Westerath H., Lentfer T., Staack M. \& Sandilands V. (2009). Qualitative behaviour assessment. In Assessment of animal welfare measures for layers and broilers (B. Forkman \& L. Keeling, eds). Welfare quality reports No. 9, EU 6th Framework Programme. University of Cardiff, Wales, 113-119.

76. Wemelsfelder F. \& Millard F. (2009). - Qualitative behavior assessment. In Assessment of animal welfare measures for sows, piglets and fattening pigs (B. Forkman \& L. Keeling, eds). Welfare quality reports No. 10, EU 6th Framework Programme. University of Cardiff, Wales, 213-219.

77. Bokkers E.A.M., de Vries M., Antonissen I.C.M.A. \& de Boer I.J.M. (2012). - Inter- and intra-observer reliability of experienced and inexperienced observers for the qualitative behaviour assessment in dairy cattle. Anim. Welf., 21, 307-318.

78. Temple D., Manteca X., Dalmau A. \& Velarde A. (2013). - Assessment of test-retest reliability of animal-based measures on growing pig farms. Livest. Sci., 151, 35-45.

79. Leach M.C., Klaus K., Miller A.L., Scotto di Perrotolo M., Sotocinal S.G. \& Flecknell P.A. (2012). The assessment of post-vasectomy pain in mice using behaviour and the mouse grimace scale. PLOS ONE, 7 (4), 1-9. doi:10.1371/journal.pone.0035656.

80. Whay H.R. (2007). - The journey to animal welfare improvement. Anim. Welf., 16, 117-122. 
81. Hemsworth P.H. \& Coleman G.J. (1998). - Human-livestock interactions. The stockperson and the productivity and welfare of intensively farmed animals. CAB International, Wallingford, United Kingdom.

82. Waiblinger S., Boivin X., Pedersen V., Tosi M.V., Janczak A.M., Visser E.K. \& Jones R.B. (2006). Assessing the human-animal relationship in farmed species: a critical review. Appl. anim. Behav. Sci., 101, 185-242.

83. Anneberg I., Vaarst M. \& Sandoe P. (2013). - To inspect, to motivate - or to do both? A dilemma for on-farm inspection of animal welfare. Anim. Welf., 22, 185-194. 